\title{
É DOCE E HONROSO MORRER PELA PÁTRIA? RITUAIS CÍVICOS E DISCIPLINA MILITAR NA GUERRA DO CONTESTADO
}

\author{
IS IT SWEET AND HONOURABLE TO DIE FOR THE \\ COUNTRY? CIVIC RITUALS AND MILITARY DISCIPLINE \\ IN THE CONTESTADO WAR
}

\author{
Rogerio Rosa Rodrigues*
}

\begin{abstract}
Resumo: O artigo tem como objetivo analisar os rituais cívicos celebrados pelo Exército brasileiro durante a repressão ao movimento do Contestado. As fontes de referência para a análise são os discursos proferidos pelos oficiais e lidos publicamente durante os exercícios militares. A hipótese defendida é de que os discursos oficiais tinham como objetivo imediato disciplinar os soldados, justificar as mortes e conferir identidade ao inimigo interno, no caso, os rebeldes do Contestado. No entanto, os mesmos rituais apontam para a estreita relação que o exército mantinha com a política nacional, em especial com o regime republicano que ajudou a implantar em 1889. A inspiração para essa estratégia vinha tanto das experiências do passado, quanto dos confrontos "corpo a corpo" com os rebeldes do sul do Brasil. Em função disso, em primeiro lugar será analisado a disciplina e militarização dos rituais promovidos pelos fiéis de São João Maria, para em seguida, destacar os elementos religiosos da atuação militar promovida no campo de batalha durante a guerra do Contestado entre setembro de 1914 e maio de 1915.
\end{abstract}

Palavras-chave: Guerra do Contestado. Rituais cívicos. Patriotismo. Disciplina. Exército.

\footnotetext{
* Professor Adjunto de Teoria da História na Universidade do Estado de Santa Catarina (UDESC). E-mail: roger_es@yahoo.com
} 


\begin{abstract}
This paper analyzes the civic rituals enacted by the Brazilian army during the repression of the Contestado movement. The analysis is based on public speeches given by army officers at military exercises. It is postulated that these public speeches aimed to discipline soldiers, justify the war casualty and shape the identity of the internal enemy, the Contestado rebels. The rituals also point to the close relationship between the army and national politics, particularly with the republican regime the army helped establish in 1889 . Such strategy was inspired not only by past experiences but also by body to body conflicts with rebels in the south of Brazil. The paper starts by looking at the discipline and militarization of rituals acted out by followers of Saint João Maria, and then highlights religious aspects of military action taken in the battlefield during the Contestado war.
\end{abstract}

Keywords: Contestado war. Civic rituals. Patriotism. Discipline. Army.

\title{
INTRODUÇÃO
}

Em ensaio sobre a psciologia do combatente brasileiro publicado na revista militar A Defesa Nacional, o general Luiz Flamarion Barreto Lima classifica os combatentes em três tipos: o mercenário, o conscrito e o voluntário. Cada tipo corresponderia a um traço psicológico dominante: "o mercenário faz a guerra por dinheiro. [...] O conscrito faz a guerra por obrigação, por imposição da lei. [...]. O voluntário é uma convicção em marcha. Integra-se na luta para obter o triunfo de um ideal." Embora publicado em 1957 e tomando como exemplo os combates travados em Canudos, o general comunga das mesmas ideias defendidas pelos oficiais que atuaram na Guerra do Contestado. Elas foram utilizadas, tanto em um caso como em outro, para justificar as perdas militares diante dos supostos fanáticos religiosos. A força do sertanejo, nessas representações, estaria na causa que abraçaram voluntariamente, enquanto a fragilidade do soldado brasileiro se fixaria no sistema da conscrição. ${ }^{2}$

Em levantamento realizado sobre a origem dos soldados que atuaram no Contestado foi possível verificar que boa parte provinha das mais diferentes regiões do país. Na fase decisiva dos combates, setembro e outubro de 1914, soldados foram convocados e incorporados às pressas. ${ }^{3}$ A maioria era estranho às condições físicas e naturais da zona de combate. Os rebeldes, por sua vez, conheciam profundamente a região, estavam acostumados ao clima frio e chuvoso do planalto catarinense e eram unidos pela crença nos poderes sobrenaturais e guerreiros de São João Maria e São Sebastião. Esse fator foi reconhecido pelos "historiadores de farda" ${ }^{\text {, }}$ tanto quanto pelos comandantes militares da época como fundamentais para as vitórias iniciais dos rebeldes sobre as primeiras expedições militares. 
Tendo em vista a comparação efetuada à epoca entre a disciplina dos rebeldes e a pouca instrução dos soldados, na primeira parte deste texto será feita uma breve descrição dos aspectos militares presentes na formação e cotidiano da irmandade religiosa para, em seguida, propor uma discussão sobre o teor religioso das comemorações cívicas realizadas pelo exército brasileiro no campo de batalha. Uma vez que as pesquisas sobre a organização social dos sertanejos já estão bastante avançadas, a fonte utilizada para a descrição dos símbolos e rituais da religiosidade sertaneja constará da bibliografia especializada, em especial as teses publicadas por sociólogos e historiadores sobre o assunto, porém acrescidas dos relatos efetuados pelos "historiadores de farda" e pela própria documentação militar. No caso das comemorações cívicas, as fontes de referências serão os discursos proferidos em campo de batalha por ocasião de festividades patrióticas. Sobre esses discursos, cabe destacar que embora tenham sido elaborados e proferidos pela alta oficialidade, seria equivocado tomá-los como expressão singular de um ou outro militar, logo, sem correspondência com a visão de mundo de muitos de seus contemporâneos civis e militares. Acredito que eles fazem parte de um discurso oficial que era ao mesmo tempo compartilhado pela cúpula militar e pela elite intelectual brasileira comprometida com a modernização do exército. ${ }^{5}$ Nesse aspecto é possível afirmar, em consonância com as referências atuais acerca da história intelectual e dos $\operatorname{conceitos}^{6}$, que tais ideias remetem a posicionamentos políticos em um contexto social específico. Conforme a abordagem de Reinhart Koselleck, são ideias forjadas em um espaço de experiência que extrapola as malhas de aço da corporação militar e que se projetam para além do singular acontecimento de combate aos rebeldes do Contestado.

\section{A SANTA IRMANDADE E A DISCIPLINA MILITAR}

A crença religiosa dos sertanejos do Contestado mereceu destaque no rol de pesquisas realizadas por aqueles que se debruçaram sobre o assunto. No momento do conflito, a sociedade clamava pelo entendimento do chamado "fanatismo", visto como caraterística comum aos habitantes do interior do país e tendo como principal causa a ignorância. Essa concepção alimentou a imaginação da sociedade civil e militar por longo tempo. Ela chegou a ganhar fundamentação científica em teses como a do médico catarinense Aujor Ávila da Luz que na década de 1950 publicou o livro "Os fanáticos" com o sugestivo subtítulo "crimes e aberrações da religiosidade dos nossos caboclos". ${ }^{7}$ Desde então, as peculiaridades da chamada religiosidade cabocla têm proporcionado interpretações diversas, quando não divergentes, cabendo a alguns pesquisadores, como Mauricio Vinhas de Queiroz (1981), a sugestão de uma autonomia completa na religiosidade dos homens e mulheres que atuaram 
no movimento do Contestado. Os ecos dessa discussão aparecem até os dias atuais. É comum, dentro e fora do campo acadêmico, falar de uma religião do homem do Contestado. ${ }^{8}$

Duglas Teixeira Monteiro, lá pelos idos de 1970, já havia questionado essa construção ao destacar que a religiosidade dos rebeldes do Contestado não se diferia da matriz religiosa de outras regiões do país. Conforme registrou:

O catolicismo popular, de um modo geral, e em sua modalidade rústica, em particular, tem suas raízes mais importantes plantadas no solo da Grande Tradição judaicocristã, onde sobressaem, às vezes contraditoriamente, a esperança messiânica do Reino de Deus numa terra renovada, e as expectativas de uma expiação individual. ${ }^{9}$

Nesse sentido, guardando suas especificidades, a manifestação religiosa dos sertanejos que viviam no planalto catarinense possui elementos presentes nas práticas rituais do catolicismo europeu e, de acordo com Monteiro, "com maior razão nas manifestações populares do catolicismo em toda a América Latina." ${ }^{10}$ Feita essas ressalvas, o pesquisador destacou a criação, no interior do movimento, do que convencionou chamar de Santa Irmandade. Esta só ganhou forma entre os sertanejos após o combate do Irani em 1912, mais precisamente a partir do momento em que os sertanejos se reuniram para aguardar a ressurreição dos monges e santos.Embora cimentada pela fé, a Santa Irmandade incorporou críticas à exploração política e econômica presente no planalto catarinense. Como bem ressaltado pelos estudos recentes, ${ }^{11}$ esses fatores foram incorporados aos poucos, de acordo com as necessidades e interesses dos homens e mulheres que aderiram o movimento. Uma série de rituais e crenças destacadamente referenciais ao conflito do Contestado, como a organização dos "Doze pares de França", a descida do guerreiro celeste São Sebastião e seu exército encantado para lutar junto aos rebeldes, a ressurreição de José Maria e de todos os que tombarem em luta durante os conflitos com os jagunços e militares, não ocorreu de imediato, em bloco, mas no processo de lutas com os "peludos" 12 e de conflitos internos entre os próprios fiéis. Foi, portanto, no enfrentamento defensivo com as forças militares estaduais, e posteriormente federal, que o movimento foi incorporando novos fiéis e novos valores e ao mesmo tempo aprimorando o seu ritual. ${ }^{13}$ Espalhados em uma vasta região de aproximadamente vinte mil quilômetros quadrados, distribuídos em vilarejos de 300 a 5 mil habitantes, o fator de aglutinação dessa comunidade era, sobretudo, a fé no monge João Maria, essa sim, firmada em uma longa tradição que antecede a organização da irmandade. ${ }^{14}$ A renovação dessa crença se dava por meio de uma liturgia extremamente rigorosa, tendo como base a disciplina militar. 
A existência do "quadro santo" é um dos mais destacados exemplos desse tipo de característica militar existente na Santa Irmandade. Constituía-se em uma praça retangular onde se situava uma igreja, tendo em cada um dos ângulos um cruzeiro assinalando os pontos significativos do seu perímetro. Em seu interior eram realizadas diariamente as "formas". Conforme a análise de Duglas Monteiro, nos quadros santos os fiéis,

Conforme critérios de sexo e de idade, combinados com critérios funcionais [...], distribuíam-se pelo terreno da praça e ali recebiam as ordens que o comandante, porta-voz direto ou indireto das potências do céu, fazia chegar até eles. Essas determinações, tanto diziam respeito a questões práticas (distribuição de tarefas, por exemplo), como a questões de conduta religiosa e moral. Era também quando se aplicavam castigos, desde a punição de faltas veniais pelo espancamento com varas, rabo-de-tatu ou a face de facões, até punições capitais. ${ }^{15}$

Além do "quadro santo", outro aspecto militar incorcorado na luta rebelde diz respeito a uma tropa de elite inspirada na leitura que os sertanejos tinham da "gesta carolíngia" denominada de "Pares de França". Para Duglas Monteiro, a influência da gesta entre os sertanejos do Contestado pode ser observada a partir de três elementos: o primeiro deles era a existência de uma guarda de elite composta por 24 homens que lutavam preferencialmente a facão. O segundo, é a informação de que o monge José Maria lia publicamente trechos da Historia de Carlos Magno e dos Doze Pares de França, seguida de Bernardo Del Cárpio que venceu em Batalha aos Doze Pares de França; o último elemento é a crença de que "ia fazer mil anos da guerra de Carlos Magno". ${ }^{16}$ Esses elementos, embora com referência ao período de vida de José Maria quando da organização do primeiro vilarejo de Taquaruçu em agosto de 1912, se consolidou em rituais que daria contornos à Santa Irmandade mais de um ano depois do combate do Irani - outubro de 1912 - e por ocasião do segundo movimento de fiéis em Taquaruçu a partir de dezembro de 1913. Esses rituais aparecerão de forma mais elaborada no vilarejo de Caraguatá que teve inicio em janeiro de 1914, mais especificamente após o ataque sangrento das forças oficiais ocorrida em fevereiro do mesmo ano que culminou na morte de centenas de rebeldes entre idosos, mulheres e crianças.

A preferência pela arma branca é um componente fundamental da militarização do ritual da "Santa Irmandade". Ela remete a leitura que os sertanejos tinham da gesta carolíngia, mas também a adaptação à cultura local, tendo em vista a familiaridade com a violência e com armas utilizadas no cotidiano do homem rural, tais como facão, canivete, punhal e armas de fogo. O manuseio de tais instrumentos foi fundamental para o bom desempenho dos 
sertanejos do Contestado em sua resistência aos ataques promovidos pela forças militares oficiais. Ao serem incorporados dentro do ritual místico e bélico dos "quadros santos", essas armas ganharam novo significado. Deixaram de ser apenas instrumentos de trabalho e de defesa, para serem alçadas à categoria de artefatos com poderes sobrenaturais. Armas poderosas contra os infiéis que teimavam em reprimir a santa religião. Esse caráter militar no interior do movimento sócio-religioso do Contestado foi fundamental para a manutenção da ordem e da fé dos sertanejos ao longo de toda a luta.

Como bem demonstrou Paulo Pinheiro Machado, essa lógica de guerra não vingou até o fim do conflito. À medida que as ofensivas oficiais se fizeram mais violentas, os fiéis tiveram que adotar posturas mais militarizadas e também renovar suas estratégias de combate e tecnologias bélicas. Isso não significou o abandono da crença no poder dos santos e monges e das intervenções sobrenaturais no momento da luta. A permanência da fé no monge como elemento de coesão até os momentos finais do movimento pode ser comprovada pela peermanência das "medidas do monge João Maria", orações de São Sebastião para fechar o corpo e patuás encontrados junto aos corpos dos rebeldes presos ou mortos em combate. Comprova-o também as benzeduras das armas e os sinais de cruz efetuadas nas munições, facões e revólveres preservados em grande quantidade em museus da região do Contestado na atualidade. Por fim, merece registro a existência, no corpo de combatentes sertanejos, de alguns oficiais da guarda-nacional, de ex-soldados da força pública, e de antigos jagunços de coronéis locais.

Outra característica marcante da postura guerreira dos sertanejos, e de grande impacto no espírito dos soldados, diz respeito aos ataques efetuados pelos sertanejos de forma furtiva aos homens ligados às forças de repressão. Ao reproduzir trechos de entrevista feita a um comerciante que conhecia quase todos os chefes rebeldes, o historiador de farda Dermeval Peixoto oferece pistas sobre a condição das tropas militares à época. Trata-se do relato do senhor Guilherme Guerth:

Chegam a noite, aproximando-se cautelosamente das linhas, exteriores dos destacamentos, estendem-se em linha de atiradores e rompem o fogo, que não raro dura até ao amanhecer, e para simularem maior número de guerrilheiros levam os adolescentes que dispõem ao modo de uma reserva, cujo destino consiste em gritarem desesperadamente "vivas a Sebastião, a S. José Maria e morras aos peludos!" Se reconhecem, porém, sua esmagadora superioridade, como aconteceu no encontro com o capitão Matos Costa, investem com firmeza, conduzidos por buzinas de caça e bandeirolas brancas, em cujo centro se desenha uma cruz de fita de cor e dando vivas alarmantes e morras ameaçadores vão-se 
abeirando dos soldados que ferem desapiedadamente a facão. ${ }^{17}$

A descrição feita acima pode ser confirmada pela documentação militar denominada"partes de combate": relatórios redigidos pelos oficiais após enfrentamento com os guerreiros de São João Maria. Nessa fonte, os militares registraram o grande barulho feito nos matos durante os ataques promovidos contra as forças oficiais. Eram os vivas aos santos e monges, cadenciados pela batida de tambores. Essa tática, além de disseminar o pânico entre os soldados, tinha como função invocar a presença dos guerreiros celestes liderados por São Sebastião. Acreditava-se que nesse momento cada guerreiro atingiria a força de cem homens. A presença da bandeira branca também fora notada em alguns relatórios de guerra. Em ataque sofrido pela $2^{\mathrm{a}}$ Companhia do $16^{\circ}$ Batalhão do Regimento de Infantaria em Canoinhas em 16/07/1914, o comandante registrou: "faltando vinte minutos para as horas cinco, quando os primeiros grupos bateram em retirada sempre aos vivas à Monarquia, à Bandeira da Misericórdia e a José Maria [...]". ${ }^{18}$

O curioso é que a partir de determinado momento os soldados passaram a adotar o "Viva a República" e "morte aos fanáticos" durante o confronto com os rebeldes. Essas palavras de ordem, ao serem repetidas, conferiam caráter político e ideológico a repressão aos fiéis. Tal como os vivas a São Sebastião, elas funcionavam como uma espécie de ladainha cívica a potencializar a força dos soldados e encorajá-los à luta. Mais que isso, elas davam contornos imaginários àqueles que deveriam ser exterminados pelas armas. Tal prática é comum a qualquer ação bélica, porém, no caso do Contestado, ela se fazia fundamental tendo em vista a deficiente preparação disciplinar dos soldados e, principalmente, as incertezas quanto a razão de exterminar cidadãos brasileiros taxados como inimigos da nação. ${ }^{19}$

As dúvidas sobre a necessidade dessa guerra perseguia a consciência de boa parte dos homens engajados nas forças de repressão. Tal questionamento se fazia presente até entre a alta oficialidade que atuou no Contestado. Muitos reconheciam a justa reivindicação dos sertanejos no que diz respeito a posse de terra, aos desmandos dos coronéis locais e a exploração da madeireira internacional Lumber and Colonization Company. O primeiro general a comandar uma ofensiva contra os rebeldes em maio de 1914, Carlos Frederico de Mesquita, deu por finalizada a ação oficial com a seguinte declaração:

Aos governos do Paraná e Santa Catarina competem, agora, com suas forças policiais, exterminar os bandidos que aparecem, limpando, assim, a zona de elementos perniciosos. Em parte, a culpa é dos referidos governos, que descuram da instrução, deixando a gnorância campear 
livremente, chegando o fanatismo a constituir grupos, como o que acabo de aniquilar numa vitória inglória. ${ }^{20}$

O oficial que o substituiu no comando entre maio e agosto de 1914, capitão Antônio Teixeira de Matos Costa, foi mais enfático ao declarar à imprensa da época:

\begin{abstract}
A revolta do Contestado é apenas uma insurreição de sertanejos espoliados nas suas terras, nos seus direitos, na sua segurança. A questão do Contestado se desfaz com um pouco de instrução e o suficiente de justiça, como um duplo produto que ela é da violência que revolta e da ignorância que não sabe outro meio de defender o seu direito". ${ }^{21}$
\end{abstract}

Embora o general Setembrino de Carvalho não tenha titubeado quando a repressão aos rebeldes, tinha consciência dos interesses politiqueiros que moviam as ordens de repressão ao movimento. Carvalho chegou a oferecer terras para aqueles que se entregassem voluntariamente. ${ }^{22}$ Assim como o comandante geral da campanha de guerra, a maioria dos historiadores de farda temiam que o exército figurasse como instrumento das oligarquias locais, exterminando os rebeldes para aumentar o poder dos coronéis. Em plena campanha de modernização militar, o que o exército menos pretendia era ver o nome da corporação atrelado a politica coronelística. ${ }^{23}$

Os tiros comemorativos eram outros elementos de forte teor bélico comum nas comunidades santas. Para além do aspecto militar, tal prática atesta o caráter de festa permanente promovido no interior das vilas. Conforme a análise de Duglas Monteiro, esse seria um dos pontos fundamentais da tradição milenarista presente no movimento do Contestado. Para esse pesquisador, os tiros e as churrascadas frequentes nos primeiros momentos da "santa irmandade" seriam sinais de que para os fiéis de João Maria o milênio de opressão chegava ao fim. Esse espírito festivo ligava a tradição religiosa dos rebeldes do Contestado com o destino fabuloso de Carlos Magno e os pares de França. ${ }^{24}$

De acordo com Mona Ozouf, a festa representa ao mesmo tempo uma repetição do passado e um prenúncio do futuro, ou seja, uma relação particular com o tempo. ${ }^{25}$ No caso do Contestado, o prenúncio do fim do milênio/fim do mundo fez do presente o momento da revelação e da festa. O júbilo pela ruptura com o passado. Para Monteiro, a festa permanente anunciada pelas churrascadas e pelas salvas de tiros nas vilas santas eram como "uma das expressões da presença real do sagrado e do contato efetivo com o sobrenatural". ${ }^{26}$

A antecipação do futuro desejado, acreditado e defendido pelos sertanejos, tem como argumento favorável o sacrifício de vidas de pessoas que acreditavam ser possível uma vida melhor naquele momento. Vale lembrar, 
que embora os fiéis promovessem uma campanha convidando a adesão de mais adeptos para a santa irmandade, a maioria dos participantes ali chegaram por vontade própria, após abandonar propriedades e pertences pessoais para juntar-se aos irmãos, cabendo mencionar que levavam consigo mulheres, filhos e pais. Era, sem dúvida, uma crença fortificada e ampliada para além da vontade individual. Tamanha devoção e entrega não se verifica entre os soldados do exército brasileiro que atuou na repressão ao conflito.

\section{TEMPO E CELEBRAÇÃO CÍVICA NO FRONT}

Em ordem publicada nos boletins internos do exército, o general Setembrino de Carvalho determinou que todas as unidades em campanha de guerra no Contestado deveriam saber tocar todos os hinos "máxime o nacional, da República e da Bandeira". ${ }^{27} \mathrm{O}$ primeiro estranhamento diante dessa publicação diz respeito a necessidade de registrar oficialmente a obrigatoriedade das bandas militares saberem os hinos cívicos do país. A decisão sugere que os mesmos não eram familiares às tropas, caso contrário, por que ordenar o aprendizado? Carvalho comandou a repressão ao movimento entre setembro de 1914 e maio de 1915. Sua expedicão oficial foi a de maior potência bélica registrada no combate aos rebeldes. Constava de um terço do efetivo do exército, seis mil militares, e dois mil vaqueanos: civis contratados sob a liderança dos coronéis locais. Para esse período, instituiu um calendário cívico no campo de batalha que incluía comemorações ao dia da Bandeira, Batalha do Tuiuti, Proclamação da República, aniversário da Constituição Republicana e dia de Tiradentes. Em suma, festividades republicanas. Se a campanha militar federal tinha como objetivo imediato reprimir a rebeldia sertaneja no sul do Brasil, em que momento se realizavam essas comemorações? Para além disso, fica a dúvida sobre os fins dos rituais cívicos em meio a uma campanha de guerra. Uma análise desses rituais, bem como dos discursos promovidos no campo de batalha, pode revelar aspectos da relação que o Exército mantinha e almejava com seus soldados, com a sociedade brasileira e com a política nacional.

O ritual incluía a execução dos hinos, salva de tiros, relaxamento dos castigos para os soldados e oficiais e, por fim, a leitura pública dos textos produzidos para celebrar a data festiva. Os discursos eram redigidos pelo comandante geral da campanha militar, e muitas vezes acrescidos por textos produzidos por oficiais comandantes das colunas móveis. ${ }^{28}$

Durante a celebração, ou performance discursiva, os discursos oficiais são integrados aos hinos cívicos, salva de tiros e relaxamento dos castigos. Tal fato justifica o uso da expressão "performance discursiva", entendida aqui como uma celebração que vai além da leitura do discurso perante os soldados. É, portanto, por meio dessa performance que a história dos soldados se materializa 
em um ritual que tem como foco incutir o amor à pátria, logo, o sacrifício e abnegação dos soldados. Além disso, essa performance discursiva molda a face do "inimigo", caracterizado como estrangeiro, infiel, anarquista, desordeiro, enfim, heréticos no reino da lei e da ordem corporificada na República.

No ritual comemorativo, são definidos os fiéis e os impuros, assim como nas formas da "santa irmandade" o "quadro santo" não só distinguia "pelados" e "peludos", mas também aqueles que deveriam expiar seus pecados. Em um dos muitos discursos publicados nos boletins de guerra, Setembrino de Carvalho destaca a comemoração do dia da Bandeira:

Se alguma festa existe aproximando os indivíduos ao pálio de irmanados sentimentos, merecedoras das honras de uma primazia, a da bandeira é sem dúvida uma delas, senão a primeira. Símbolo da nossa nacionalidade, onde quer que a vejamos, invade-nos a grata lembrança de nossa pátria cara, cuja existência se prolonga desde o vasto território do Amazonas às águas do Prata. Até o estrito espaço que ela ocupa ao ondular nas popas dos navios, na fachada dos consulados e nas procissões de homenagem em terras estranhas. Maior talvez, que para os povos é para nós militares a significação da bandeira nacional.

Este símbolo em que a arte lavrou seus traços estéticos no agrupamento por sua vez simbólico da áurea riqueza num belo quadro de esperanças sobre a região celeste que o cruzeiro assinala, é tanto mais significativo porque ao vê-lo ondular por sobre as baionetas luzidias, tremular frenética ao galopar da cavalaria conduzindo lanças à carga, ou volutear graciosamente no mastro das naves de guerra, presidindo o rugir do canhão, hoje em Salva, invade-nos a alma de eletrizantes vibrações patrióticas, que ao ser inteiro, vivo, ardente, entusiasmo transmite, indomável força gera e a sua sagrada defesa impele. De apoucada monta seria as espessuras dos baluartes, a têmpera das cúpulas, o aguçado das baionetas; apoucado seria o valor das couraças, o volume dos canhões, o depósito das medalhas dos vasos de guerra; estes e aqueles vasos e baluartes, belas concepções de arte consorciadas às necessidades bélicas, ostentando muralhas nas encostas ou planícies, e alteando costados no azul dos mares, inofensivas esfinges seriam, acaso o soldado, o marinheiro, haurindo sempre impressões de nobreza e valor na pátria bandeira, aí não estivesse para dar-lhes movimento, dar-lhes calor, dar-lhes Vida! ${ }^{29}$

Palavras como irmanados sentimentos, procissões, esperanças, região celeste, alma, sagrada defesa, são algumas expressões de forte conteúdo 
religioso. Nesse texto o oficial, tal como um pastor, enumera as características da bandeira e o sentimento que ela deve suscitar, fazendo do patriotismo uma virtude máxima das classes armadas, e dos seus homens, uma espécie de discípulos da nação, os únicos capazes de pagar com tributo de sangue o amor à pátria.

Segundo Reinhart Koselleck o conceito moderno de patriotismo remonta ao início do século XVIII. No contexto da Revolução Francesa ele designava o amor ativo à terra, à Constituição e à República. Nesse período o sentimento patriótico foi elevado a uma categoria política e a pátria se converteu em sujeito coletivo ao emancipar-se e sobrepor-se ao soberano. Em Kant, prossegue o autor, "o patriotismo exige tomar partido, ou seja, tomar partido pelo Estado constititucional republicano". ${ }^{30} \mathrm{~A}$ análise do historiador alemão vem ao encontro das informações colhidas sobre as comemorações cívicas no Contestado. O exército identifica o patriotismo como defesa da lei e da ordem, um amor incondicional pela República, pela Constituição e seus emblemas. É mais que uma identificação com a terra. É um sentimento comum que unifica e impele ao sacrifício. Ela possui corpo próprio "cuja existência se prolonga desde o vasto território do Amazonas às águas do Prata", tal como exposto no discurso reproduzido acima.

A bandeira é o símbolo máximo da pátria desejada, e os militares, os verdadeiros patriotas. A ênfase dada ao papel dos militares remete à complicada questão do que é ser cidadão na Primeira República. Na campanha movida pela Liga de Defesa Nacional por esta época, o poeta Olavo Bilac defendia a implementação do serviço militar obrigatório como forma de incutir o sentimento patriótico no povo brasileiro. No discurso que proferiu na Faculdade de Direito de São Paulo em 9 de outubro de 1914 destacou: "A caserna é um filtro admirável, em que os homens se depuram e apuram: dela sairiam conscientes, dignos, brasileiros, esses infelizes sem consciência, sem pátria, que constiuem a massa amorfa e triste da nossa multidão". ${ }^{31}$ Se faltava patriotismo ao povo brasileiro, o mesmo não se identificava, conforme Bilac, entre os soldados. Eis como ele se manifestou aos oficiais do Clube Militar do Rio de Janeiro 6 de novembro de 1915 "em falta de um perfeito patriotismo coletivo, consciente e coesivo, ao menos há no Brasil, felizmente, a bravura própria, o pundonor pessoal, um patriotismo individual". ${ }^{32}$

A partir das indicações de Bilac e da performance discursiva do dia da Bandeira celebrado no Contestado é possível destacar ainda outro ponto em comum que circulava nas ideias e na prática militar, a concepção de guerra como elemento de coesão, como forma de identificação com a pátria. No mesmo discurso proferido no Clube Militar o poeta assinalou “a guerra, apesar de todos seus males, seria uma ventura, porque seria uma formidável força de ligação nacional". ${ }^{33}$ Dentro dessa lógica, Setembrino de Carvalho e seus comandantes contribuíam para a construção do patriotismo republicano, logo, 
para a fabricação do cidadão moderno no Brasil. Ao que tudo indica, esse foi um dos elementos fundamentais da insistência das performances discursivas em prol das celebrações cívicas no campo de batalha durante a repressão aos rebeldes do Contestado.

Outro aspecto apontado por Koselleck sobre a semântica do conceito de patriotismo diz respeito aos usos modernos de um poema de Horácio que diz que é "doce e honrado morrer pela pátria" (Dulce et decorum est pro patria mori). A frase sugere o sacrifício pela pátria ou a ideia de que em casos de doar a vida em luta o interesse comum se sobrepõe ao individual. A apropriação dessa frase se deu em função de uma articulação entre motivos políticos e religiosos. Segundo o autor "a motivação da Antiguidade se viu reforçada pela cristã à medida em que a morte - pela pátria - se legitimou adicionalmente com a outra morte - pelo reino dos céus -, algo que em nossa modernidade foi plasmado na expressão morrer em nome da sagrada pátria". ${ }^{34}$

Esse é outro aspecto particularmente destacado nas performances discursivas do Contestado, tal como aparece na comemoração ao Dia da Bandeira:

Significativamente e solene é a homenagem que nesta data o país todo rende à bandeira nacional, esse símbolo vibrante expressivo, consubstanciação de nossa nacionalidade, de nossa Pátria, pela qual devemos dar o nosso sangue, a nossa vida, oferecendo-lhes em holocausto num rasgo de patriotismo desprendimento e abnegação estóica toda vez que a sua dignidade e prestígio se sentirem ameaçados ou vilipendiados pelo estrangeiro audaz, no voltar contra ela seus gestos insolentes e as suas armas mortíferas e devastadoras. ${ }^{35}$

Tanto no limiar da modernidade europeia quanto durante a campanha de guerra contra os fiéis de João Maria, o vínculo entre patriotimo e cristianismo é reforçado. Ele aparece no campo de batalha ao elevar o soldado à categoria de mártir da nação.Tiradentes é evocado como exemplo, aparecendo como aquele que "ofereceu sua vida em holocausto defendendo o ideal de seus irmãos". ${ }^{36}$

Era comum, durante as festividades cívicas do Contestado, celebrar uma missa. Dessa forma, pátria, República, Igreja, Constituição e ideologia militar são convertidos, por meio da performance discursiva, em elementos concretos, com vistas a incentivar a ação dos soldados, forjar o espírito patriótico e construir a imagem do inimigo a combater.

Outra estratégia comum, presente nas performances discursivas realizadas no Contestado, diz respeito ao uso de experiências do passado para legitimar as ações no presente e incutir sentimento cívico-religioso nos soldados. É o que se verifica na comemoração do 15 de novembro: 
Passa hoje mais um ano de realização do grande sonho dos Brasileiros! Fazem 25 anos que foi proclamada a República Brasileira - a obra portentosa de Benjamim Constant e generalíssimo Deodoro da Fonseca. De há muito que os filhos de Santa Cruz vinha lutando perseverantemente pela vitória do nosso povo, em sua vontade: o direito da Nação se governar por si e a igualdade de todos perante a lei. [...] E a história registra as sucessivas revoluções de Norte ao Sul sempre com o mesmo objetivo. Por isso Benjamim Constant e Deodoro da Fonseca são os maiores filhos de nossa grandiosa Pátria.

Salve o advento de $1889 .{ }^{37}$

O texto afirma que a Proclamação da República foi conquistada graças a revoluções que vinham ocorrendo de Norte a Sul do Brasil, cabendo ao exército, representado pelo general Deodoro da Fonseca, o papel de protagonista desse enredo. Os esforços em relacionar os militares com o episódio de mudança de regime apontam para o protagonismo do exército na derrubada da monarquia, e, por conseguinte, sugerem que os oficiais foram os grandes revolucionários. À representação de um passado de trevas e de isolamento é contraposta a de um país do futuro em que ordem e progresso marchariam irremediavelmente, pois a partir de 15 de novembro de 1889 o povo brasileiro teria assumido as rédeas de sua própria história. Eis como outro discurso promovido no campo de batalha faz eco à essa ideia:

Passando-se hoje o $25^{\circ}$ aniversário da Proclamação da República, à cujo evento estão indissoluvelmente ligadas as forças armadas da nação, congratulo-me com as forças do meu comando pelo transcorrer dessa memorável data, que lhes recordará diuturnamente essa transição máxima em nossa vida de povo livre a refletir-se no progresso e engrandecimento do Brasil, que desde então se enveredou por nova senda a interromper-lhe o isolamento e desconhecimento em que jazia, ao tempo do regime decaído. ${ }^{38}$

Esses discursos revelam o papel que os militares se atribuíam no desenvolvimento político e social do país. Essa afirmação se fazia necessária diante do contexto militar vivido no momento da repressão ao movimento do Contestado, uma vez que desde o fim do governo de Floriano Peixoto, os militares foram alijados da política nacional, e com eles, o projeto que tinham para a nação. ${ }^{39}$ As atuações conturbadas dos dois primeiros presidentes militares fixaram uma imagem negativa da participação do exército na liderança da política nacional. A campanha pela eleição presidencial envolvendo o Marechal 
Hermes da Fonseca em 1910, assim como sua atuação como líder político (1910-1914), reacendeu o interesse dos militares pela política nacional.

A criação de um comitê de comemoração à memória de Deodoro da Fonseca no IHGB, a publicação de uma biografia do generalíssimo no Jornal do Commercio do Rio de Janeiro ${ }^{40}$, a criação de museus militares ${ }^{41}$, a campanha pelo sorteio militar obrigatório ${ }^{42}$, a atuação dos "jovens turcos" e o projeto de profissionalização do exército ${ }^{43}$, são experiências indicativas da constituição de uma memória militar republicana e do desejo dos oficiais do exército em retomar as rédeas da política no Brasil. Tudo isso deságua nos discursos oficiais impressos na Guerra do Contestado e oferece indícios que destacam o papel significativo que esse episódio teve no projeto de modernização militar, bem como no desenvolvimento da nação brasileira na Primeira República. ${ }^{44}$

Essa articulação entre passado e futuro, ou entre o que Koselleck chama de "espaço de experiência e horizonte de expectativas" citado discurso de Bilac no Clube Militar do Rio de Janeiro ao finaliza-lo de forma retumbante com as seguintes palavras:

Peço-vos, senhores, que vos levanteis. Com toda a alma, com toda a crença e com toda a esperança, saudemos o passado glorioso do Brasil, que resplandece em vossos uniformes; o presente sofredor do Brasil, que enche todos os nossos corações; e o futuro incomparável do Brasil, que viverá no orgulho dos nossos descendentes, - Grande Pátria, que será forte para ser boa, armada para ser justa, e rica para ser generosa! $!^{46}$

É nesse contexto que deve ser inserida as comemorações cívicas implementadas pelos oficiais no campo de batalha. Mais que a possível excepcionalidade desse ritual no front, vale destacar o conteúdo dos discursos proferidos, pois o culto cívico por ele implementado indica uma conexão dos ideais militares com a política nacional. Além disso, a performance discursiva do Dia da Bandeira e da Proclamação da República informa sobre as estratégias de construção do inimigo nacional, representado pelos rebeldes do Contestado, ao mesmo tempo que a relação do exército com a história republicana do país.

\section{CONSIDERAÇÕES FINAIS}

A ritualização das manifestações militares é um componente importante da disciplina e consequente hierarquização das relações, logo, é de se esperar discursos e manifestações cívicas em instituições como o exército. Porém, o fato deles serem mantidos no campo de batalha sugere uma estratégia disciplinar que ultrapassa os objetivos imediatos de "pacificar" o sul do Brasil. Ele tinha 
em mira formar, por meio da liturgia cívica, os soldados brasileiros e atrelar a história do exército à história do Brasil.

Como atores privilegiados do culto cívico, os soldados ganhavam um passado de batalhas e de defesa pela liberdade representada pelo regime implantado. Com isso construía-se o roteiro cívico/religioso do exército assegurando o papel que o mesmo ocuparia nessa intrigante, e não menos confusa peça que foi a atuação dos militares na Proclamação da República nas primeiras páginas de sua história.

Para além de construir uma imagem de bandido para os fiéis de João Maria, era fundamental justificar as baixas militares em campo de batalha. Se entre os guerreiros sagrados da "santa irmandade" havia a crença de que os homens tombados em combate não morriam, mas "passavam", ou seja, juntavam-se ao glorioso exército encantado de São Sebastião, nos discursos cívicos, a morte dos soldados do exército era como um sacrifício ao deus Pátria, um sinal da devoção dos seus mais abnegados seguidores.

\section{NOTAS}

1 LIMA, Luiz Flamarion Barreto. A Defesa Nacional. Rio de Janeiro, 1957. p. 82.

2 As críticas ao voluntariado do serviço militar no Brasil provinha da alta oficialidade brasileira e remonta ao final do século XIX. Ela faz eco ao discurso de modernização militar proposto ao Brasil desde o fim da Guerra do Paraguai. Sobre o assunto, consultar BEATTIE, Peter M. Tributo de sangue: exército, honra, raça e nação no Brasil, 1864-1945. São Paulo: EDUSP, 2009.

3 Para uma discussão mais minuciosa sobre o número de soldados e sua incorporação às forças de repressão aos rebeldes do Contestado, ver a tese de RODRIGUES, Rogério Rosa. Veredas de um grande sertão: a Guerra do Contestado e a modernização do Exército brasileiro. Tese (Doutorado em História), UFRJ, Rio de Janeiro, 2008.

${ }^{4}$ Categoria criada por Rogério Rosa Rodrigues para referir-se aos oficiais militares que atuaram na repressão ao movimento do Contestado com o objetivo de construir narrativas históricas sobre o conflito. Para maiores detalhes consultar RODRIGUES, Rogério Rosa. As trincheiras das palavras: os historiadores de farda e as narrativas históricas sobre o Contestado. In: VALENTINI, Delmir José; ESPIG, Marcia Janete; MACHADO, Paulo Pinheiro (Orgs.). Nem fanáticos, nem jagunços: reflexões sobre o Contestado (1912-1916). v. 1. Pelotas: Editora da Universidade Federal de Pelotas, 2012. p. 237-261.

5 Aqui vale citar a Liga de Defesa Nacional na figura de Olavo Bilac e tantos outros intelectuais brasileiros engajados na campanha de modernização do exército brasileiro. Sobre o assunto CAPELLA, Leila Maria Correa. As malhas de aço no tecido social: a revista "A Defesa Nacional" e o serviço militar obrigatório. Dissertação (Mestrado em História), Universidade Federal Fluminense, Niterói, 1985.

${ }^{6}$ Refiro-me aqui em especial à concepção de história dos conceitos e história social defendida por KOSELLECK, Reinhart. História dos conceitos e História social. In:__ . Futuro passado: contribuição à semântica dos tempos históricos. Rio de Janeiro: Contraponto/PUCRio, 2006. p. 97-118. 
7 Para além do subtitítulo, o mesmo autor acrescentou entre parêntesis "Contribuição para a antropossociologia criminal e da história do movimento dos fanáticos em Santa Catarina. A edição original data de 1952 . No ano de 1999 a editora da Universidade Federal de Santa Catarina publicou a segunda edição revisada, com posfácio do historiador catarinense Walter Piazza. Sobre o assunto consultar: LUZ, Aujor Ávila da. Os fanáticos: crimes e aberrações da religiosidade dos nossos caboclos. 2. Ed. Florianópolis, 1999.

8 A ideia de fanatismo foi duramente criticada pelas pesquisas acadêmicas que sucederam a análise de Aujor Ávila da Luz, conforme se verifica nas pesquisas efetuadas por MONTEIRO, Duglas Teixeira. Os errantes do novo século. São Paulo: Livraria Duas Cidades, 1974; QUEIROZ, Maria Isaura Pereira de. La "guerre sainte” au Brésil: le mouvement messianique du Contestado. São Paulo: FFCL-USP, 1957; QUEIROZ, Maurício Vinhas de. Messianismo e conflito social: a guerra sertaneja do Contestado 1912-1916. 3. ed. São Paulo: Ática, 1981, e o mais recente trabalho publicado sobre o assunto In: VALENTINI, Delmir José; ESPIG, Marcia Janete; MACHADO, Paulo Pinheiro (Orgs.). Nem fanáticos, nem jagunços: reflexões sobre o Contestado (1912-1916). Pelotas: Editora da Universidade Federal de Pelotas, 2012.

9 MONTEIRO, Duglas Teixeira. Um Confronto entre Juazeiro, Canudos e Contestado. In: FAUSTO, B. (Org.). História geral da civilização brasileira. O Brasil Republicano. Sociedade e Instituições (1889-1930), t. 3, vol. 2. São Paulo: Difel, 1977. p. 41.

${ }^{10}$ Ibidem.

${ }^{11}$ As questões referentes ao processo de constituição das crenças e rituais presentes na Santa Irmandade podem ser encontradas no livro MACHADO, Paulo Pinheiro. Lideranças do Contestado: a formação e a atuação das chefias caboclas (1912-1916). Campinas: Editora da Unicamp, 2004, bem como em ESPIG, Marcia; MACHADO, Paulo Pinheiro (Orgs.). A guerra santa revisitada: novos estudos sobre o movimento do Contestado. Florianópolis: Ed. UFSC, 2008.

${ }^{12} \mathrm{Na}$ linguagem cabocla os peludos seriam os “infiéis" ligados às forças militares. A designação de pelados para os seus guerreiros deve-se ao fato de eles cortarem os cabelos ao aderir a irmandade.

${ }^{13}$ MACHADO, op. cit., 2004, destacou duas fases de lideranças no movimento. A primeira em que os valores religiosos se sobrepuseram e conformaram a organização do movimento rebelde. Nesse momento, as lideranças eram escolhidas em função de seu contato com o monge e com os santos. Ele foi chamado de "tempo do fanatismo". A segunda fase não eliminou a crença religiosa, mas pelas próprias condições de repressão oficial a escolha das lideranças teve que colocar em primeiro plano os fatores guerreiros. Esse foi denominado de "tempo do jaguncismo".

${ }^{14}$ É o que tem sido comprovado pelos estudos recentes de KARSBURG, Alexandre de Oliveira. O eremita do novo mundo: a trajetória de um eremita italiano na América do século XIX. Tese (Doutorado em História), UFRJ, Rio de Janeiro, 2012. A crença em São João Maria não só antecede como ultrapassa o movimento do Contestado. Conforme demonstra Alexandre Karsburg, ela remonta a meados da década de 1840 quando da passagem do primeiro monge João Maria de Agostini pelo planalto catarinense.

${ }^{15}$ MONTEIRO, op. cit., 1974, p. 174.

${ }^{16}$ Ibidem, p. 111. A historiadora Márcia Janete Espig, em sua dissertação de mestrado, investigou essencialmente a influência da gesta carolíngia na organização social/religiosa dos caboclos do Contestado. Seu trabalho tentou mapear os textos e as formas de leitura praticados 
pelos fiéis. Para maiores detalhes ver ESPIG, Márcia Janete. A presença da gesta carolingia no movimento do Contestado. Canoas: Ed. ULBRA, 2002.

${ }^{17}$ PEIXOTO, Dermeval. A campanha do Contestado. v. 2. Curitiba: Fundação Cultural, 1995. p. 27.

${ }^{18}$ Parte de Combate, Arquivo Histórico do Exército, Caixa n 5536.

${ }^{19}$ Sobre a disciplinarização dos soldados que atuaram na guerra do Contestado destaca-se o trabalho de RODRIGUES, Rogério Rosa. Os sertões catarinenses: embates e conflitos envolvendo a atuação militar na Guerra do Contestado. Dissertação (Mestrado em História), UFSC, Florianópolis, 2001.

${ }^{20}$ Apud SOARES, José Octaviano Pinto. Guerra em sertões brasileiros. Rio de Janeiro: Papelaria Velho, 1931.p. 72.

${ }^{21}$ Apud MACHADO, op. cit., p. 249.

${ }^{22} \mathrm{O}$ documento foi distribuído em forma de folheto quando da chegada de Setembrino de Carvalho ao palco do confito (setembro de 1914). Ele foi reproduzido nas obras dos "historiadores de farda", tal como Dermeval Peixoto, op. cit., 1995 e J. O. Pinto Soares, op. cit., 1931.

${ }^{23}$ Esse era o temor inicial, no entanto, ao fim do conflito o que ocorreu foi uma aliança do exército com os coronéis e seus jagunços, portanto, uma solução baseada na conformação do status quo das elites locais. Sobre as relações da campanha do Contestado com a modernização militar do exército vide a tese de doutorado de RODRIGUES, op. cit., 2008.

${ }^{24}$ Monteiro tece algumas diferenças entre as categorias messianismo e milenaristo e argumenta a favor de um caráter mais milenarista no conflito do Contestado. Para maiores detalhes sobre esse debate consultar MONTEIRO, op. cit., p. 75.

${ }^{25}$ OZOUF, Mona. A festa sob a Revolução Francesa. In: LE GOFF, Jacques; NORA, Pierre (Orgs.). História: novos objetos. Rio de Janeiro: Francisco Alves, 1980. p. 216-232

${ }^{26}$ MONTEIRO, op. cit., p. 170.

${ }^{27}$ Ordem do Dia n. 72, 25/11/1914, Arquivo Histórico do Exército, Caixa n. 5533.

${ }^{28}$ A partir do comandando de Setembrino de Carvalho nas operações contra os rebeldes do Contestado (setembro de 1914), as forças de repressão foram divididas em quatro colunas móveis chamadas de colunas norte, sul, leste e oeste. Cada coluna era comandada por um coronel e possuía em seus quadros um total de mil e quinhentos a dois mil homens. Sendo estes soldados do exército e tropas civis contratadas na região. A composição das colunas foram analisadas no capítulo 5 da tese de doutorado de RODRIGUES, op. cit., p. 306-363.

${ }^{29}$ Ordem do Dia no 39, 25/11/1914, Arquivo Histórico do Exército, Caixa no $5531-B$.

${ }^{30}$ KOSELLECK, Reinhart. Historias de conceptos: estudios sobre semántica y pragmática del lenguaje político y social. Madrid: Trotta, 2012. p. 147.

${ }^{31}$ BILAC, Olavo. A Defesa Nacional (discursos). Rio de Janeiro: Biblioteca do Exército Editora, 1965. p. 42.

${ }^{32}$ Ibidem, p. 38

${ }^{33}$ Ibidem, p. 38

${ }^{34}$ KOSELLECK, op. cit., 2012. p. 151.

${ }^{35}$ Ordem do Dia n ${ }^{\circ} 66,19 / 11 / 1914$, Arquivo Histórico do Exército, Caixa nº 5533. 
${ }^{36}$ Ordem do Dia no 62, 15/11/1914, Arquivo Histórico do Exército, Caixa no 5533.
${ }^{37}$ Ordem do Dia n ${ }^{\mathrm{o}} 52,15 / 11 / 1914$, Arquivo Histórico do Exército, Caixa no $5531-\mathrm{C}$.
${ }^{38}$ Ordem do Dia n ${ }^{\mathrm{o}} 62,15 / 11 / 1914$, Arquivo Histórico do Exército, Caixa no 5533 .

${ }^{39}$ Sobre o projeto dos militares para a República ver CARVALHO, José Murilo de. A formação das almas: o imaginário da república no Brasil. São Paulo: Companhia das Letras, 1990 e VISCARDI, Claudia Maria Ribeiro. O teatro das oligarquias: uma revisão da "política do café com leite". Belo Horizonte: C/Arte, 2001.

${ }^{40}$ Trata-se da biografia escrita por Ernesto Sena. Ela foi publicada posteriormente em livro, conforme SENNA, Ernesto. Deodoro: subsídios para a História. Brasília: Editora UnB, 1981.

${ }^{41}$ Gustavo Barroso defendia a criação de um museu militar no Brasil. Sua proposta deu origem a criação do Museu histórico nacional no Rio de Janeiro. O acervo deste museu, por sua vez, compunha-se, em sua maioria, de artefatos militares. Sobre o assunto consultar BITTENCOURT, José Neves. Cada coisa em seu lugar: ensaio de interpretação do discurso de um museu de história. Anais do Museu Paulista, São Paulo, v. 8/9, n. 9, p. 151-174, 2003.

42 Trata-se da criação em 1916 da Liga de Defesa Nacional, tendo a frente o nome de Olavo Bilac. Sobre o assunto, consultar CAPELLA, op. cit., 1985.

43 "Jovens turcos" é o nome dado a oficiais do exército que receberam treinamento na Alemanha. Eles foram responsáveis pela criação da revista militar A Defesa Nacional (1913). Esse periódico foi criado para defender a modernização do exército brasileiro nos moldes da força militar europeia, em especial a alemã. Sobre o assunto consultar CARVALHO, José Murilo de. Forças armadas na Primeira República: o poder desestabilizador. In: FAUSTO, Boris (Org.). História Geral da Civilização Brasileira. 4. ed. São Paulo: Difel, t. 3, v. 2, 1990. p. 181-234 e CAPELLA, op. cit., 1985.

${ }^{44} \mathrm{O}$ período da Guerra do Contestado coincide com o momento de modernização do exército e com a crise do sistema oligárquico nacional. Conforme VISCARDI, op. cit., 2001, nas primeiras décadas do século XX o Catete, representado pelo Presidente eleito, e o exército, disputavam força na decisão das lides políticas no país. A década de 1910, em particular, é marcada por profundos questionamento sobre "a república que não foi”. As críticas provinham de pensadores como Euclides da Cunha, Olavo Bilac, Lima Barreto e Alberto Torres. Sobre o assunto consultar RODRIGUES, op. cit., 2012.

${ }^{45}$ KOSELLECK, op. cit., 2006. p. 305-328.

${ }^{46}$ BILAC, op. cit., p. 42.

Artigo recebido em novembro de 2012. Aceito em dezembro de 2012. 